\title{
INFÂNCIA CRÔNICA
}

Amanda Pontes Figueiredo ${ }^{\mathrm{i}}$ Fernanda de Almeida ${ }^{\text {ii }}$ Flávia Fernanda Ferreira de Lucenaiii

\begin{abstract}
RESUMO: O livro "Infância Crônica", organizado por Raíza Venas e Rita Ribes, publicado pela Editora NAU no ano de 2019, reúne uma coletânea de 35 crônicas escritas por pesquisadores que compõem o Grupo de Pesquisa Infância e Cultura Contemporânea, no projeto "Fisionomias da infância: experiências cotidianas, alteridades e deslocamentos", desenvolvido na Faculdade de Educação da Universidade Estadual do Rio de Janeiro - UERJ. Os pesquisadores têm como foco as relações entre criança e cultura, elegendo como fonte de "inspiração" acontecimentos do mundo contemporâneo para a escrita das crônicas, que retratam as crianças e suas relações com a cidade.
\end{abstract}

Palavras-chave: Infância; Crianças; Crônicas; Walter Benjamin; Antônio Cândido.

\begin{abstract}
The book "Chronic Childhood", organized by Raíza Venas and Rita Ribes, published by Editora NAU in 2019, brings together a collection of 35 chronicles written by researchers that form the Childhood and Contemporary Culture Research Group, in the project "Physiognomy of childhood: everyday experiences, differences and displacements", developed at the Faculty of Education of the State University of Rio de Janeiro - UERJ. The researchers focus on the relationship between children and culture, choosing as source of "inspiration" events from the contemporary world for the writing of chronicles, which portray children and their relations with the city.
\end{abstract}

Keywords: Childhood; Children; Chronicles; Walter Benjamin; Antonio Cândido.

Essa coletânea é resultado de uma complexa investigação coordenada por Rita Ribes no projeto "Fisionomias da infância: experiências cotidianas, alteridades e deslocamentos". Com larga experiência em pesquisa com crianças e formação de professores, Rita Ribes é uma das coordenadoras desse projeto e também assina por oito de suas crônicas. A primeira tem como título "Verbete: criança". Nela a autora relata o contraste social na vida de dois grupos de crianças. Um formado por vendedores de doces na escadaria da Biblioteca Nacional, e o outro constituído por alunos de uma escola particular que, junto com suas professoras, foram conhecer esse e dentre tantas, uma significativa reflexão é proposta quando uma das professoras grita para a autoridade policial retirar o primeiro grupo do caminho, de modo que o segundo pudesse passar. A crônica torna visível a vulnerabilidade social a que estão expostas algumas crianças,

2020 Bargas; Ayoub; Assaritti, Scarazzatto, Assis. Este é um artigo de acesso aberto distribuído sob os termos da Licença Creative Commons Atribuição Não ComercialCompartilha Igual (CC BY-NC-4.0), que permite uso, distribuição e reprodução para fins não comerciais, com a citação dos autores e da fonte original e sob a mesma licença 
levando-as à situação de exclusão de acesso a espaços que originalmente também são delas. Dando continuidade ao tema, em "A cidade que se muda das pessoas", Ribes relata uma cena diariamente presenciada por ela na esquina de uma rua: uma família vivendo numa casa que era possível montar e desmontar, organizada em cima de uma carroça. Pai, mãe e filha. Certo dia, com a cama já posta, a menina dormindo num cantinho do colchão sobre a carroça, pai e mãe assistem novela num celular. Dois transeuntes engravatados ironizam: "celular melhor que o meu, nhein!". Neste momento, a facilidade que algumas pessoas possuem para perceberem objetos, quando na verdade deveriam perceber seres humanos toma a autora de sobressalto. Seguindo a roda da vida, mais adiante aquela família já não se encontrava ali, outra havia se instalado, novos moradores, também trazidos pela crise provocada pelo golpe de 2016, conclui a autora.

Em "Segredos", Ribes retrata a relação de carinho, cumplicidade e amizade entre mãe e filha que vivem a vender doces nos sinais de trânsito da cidade. Enquanto esperam o sinal abrir, mãe sentada na calçada, filha sentada no colo da mãe, trocam carinhos a partir de "segredos" contados ao pé do ouvido. É que, apesar dos obstáculos, prevalece o cultivo do amor.

Na crônica seguinte "Convescote", Ribes narra a rotina de uma mãe e seu filho na casa de sua patroa, durante a semana, antes de irem embora. Mãe e menino moram longe e a creche é perto do trabalho; a criança passa grande parte do dia na creche e nela faz todas as refeições, por isso a patroa não se incomoda. Quando chega, ainda ajuda sua mãe a lavar a louça. "Muito boa a creche”, disse certa vez a Senhora." No próximo ano, a criança irá para escola e a patroa já demonstra preocupação, pois não é o dia todo. O menino chama sua mãe para ir embora, ressaltando que é sexta de Abolição, que para o leitor pode ter duplo sentido, podendo ser uma alusão ao bairro onde moram ou a situação de trabalho que vive sua mãe.

“Combo". Para Ribes, a ideia de "combo" está muito presente no mundo moderno, mas acredita que esse conceito nem sempre combina os elementos que o compõem. De forma analógica, relata fato vivenciado em um restaurante australiano, quando um combo de pessoas adentrou o espaço: cinco adultos e três crianças. Adultos tagarelando, crianças com tablets nas mãos. Alimentação feita sem tirarem os olhos dos aparelhos. Pausa para o "parabéns para você", mas logo retornam à condição inicial. Ao saírem com os olhos nos tablets, fones nos ouvidos, sem cruzarem olhares, sem dizerem uma só palavra, seguem os adultos como parte do combo. Com tal ação, as crianças pareciam segredar ser parte de um outro combo.

Em "Ir às compras", Ribes traz uma analogia a partir do que certa vez foi escrito por Bartolomeu Campos de Queiroz, quando disse que "nascera com 57 anos. É que se somavam, à 
sua, a história dos 34 anos vividos por seu pai e os 23 de sua mãe. Sua existência iniciava-se, então aos 57 anos de idade, tendo por herança a arte combinatória das histórias que o precederam”. Pois, para a autora, até ele iria se espantar ao ver entrar num supermercado uma menina com seus 488 anos acumulados em menos de seis anos de existência. A menina trazia consigo o destino dos seus ancestrais, que foram escravizados e tratados como mercadoria no Brasil.

Na breve crônica "Pipocas", Ribes relata o que observou durante compra e venda de pipocas na rua. Mãe e duas filhas param para comprar pipoca, atraídas pelo cheiro. Enquanto as pipocas nascem, o olhar do pipoqueiro encontra o peito da menina maior espocando sob o vestidinho; no mesmo momento, também encontrou o olho da menina. Pacotinhos entregues, a mãe realiza o pagamento quando a filha menor já estava com o pacote pela metade. O pipoqueiro completa o pacote da criança e agradece sorrindo. Duas outras mulheres comentam entre si que "ele gosta de criança, ele gosta de criança...".

"Sem nome", a última crônica do livro escrita por Ribes, traz uma importante reflexão acerca das crianças representadas através das crônicas escritas nesse livro. Estas poderiam ser comparadas a Rudeiras, mas não! Não podem ser. Estas crianças não são visíveis aos nossos olhos, não são classificadas, não têm quem as descreva e assim continuam sem nome. "E como é dificil honrar os sem nome”, diz a autora.

“Com mãestria", "Do jeito que tá, do jeito que dá", "Des-perdida" e "O pequeno notável" intitulam as quatro crônicas escritas pela outra organizadora do livro, Raíza Venas, que visibiliza em suas crônicas as crianças no contexto das rodas de samba da cidade do Rio de Janeiro. Na primeira, ela dá destaque ao menino considerado o "Mascote do Samba", figurinha certa nos pagodes do subúrbio, um percussionista antigo sustentado pelo novo da infância, que toca muito e de tudo, do tamborim ao pandeiro. De sorriso tímido, tem uma mãe orgulhosa, que reconhece o talento do filho, mas não rende muitos elogios, pois para ela o menino é apenas o seu filho. Nessa condição infantil, de ser astro e ser filho, "na ópera dos malandros, a mãe é o maestro", pois em casa quem fala alto é a mãe e a banda toca conforme seus desejos.

Em “Do jeito que tá, do jeito que dá", Venas apresenta uma situação que lhe saltou aos olhos. Ela, suburbana grávida de sete meses, foi ao samba na Glória com uma amiga. Chegando lá constatou uma roda de bons músicos, cerveja cara, gente branca e nenhuma criança, pois já era tarde e passava das dez da noite. De repente avistou um menininho dormindo em uma cama improvisada de duas cadeiras de plástico, no sereno, enquanto os pais vendiam pastel no evento. Passado um tempo, sem conseguir entrar na roda de samba, Venas viu o momento em que o 
menino despertou e recusou a água que sua mãe ofereceu. Em seguida a mãe foi até o bar do evento comprar refrigerante e descobriu que teria que comprar o copo do evento junto com o refrigerante, pois por se tratar de um "Eco Samba" não havia comercialização de descartáveis. A mãe, sem opção, efetuou a compra. O menino em sua cama de cadeiras brincou com o copo de neon, "do jeito que tá e do jeito que dá".

"Des-perdida" é a terceira crônica de Venas, na qual apresenta a roda de samba dos meninos do PedeTeresa, samba considerado o ponto de encontro de gente de toda a cidade. Na roda de samba há barraquinhas de comida, bar, camelôs e crianças - quase sempre negras vendendo drops no meio do povo. E o título "Des-perdida" se dá pelo fato de os músicos pararem de tocar, pois na beira da roda encontrava-se uma menina com balas nas mãos, chorando, perdida de sua tia. "Era uma menina que sempre esteve ali, sozinha, vendendo doces. Mas que, ao ter seu nome anunciado no microfone por estar perdida, foi enxergada”. Mas esse tempo se escoa entre o samba que retorna e o primo que a leva pela mão para ser de novo apenas mais um camelô na noite da Praça Tiradentes. Por último, em "O pequeno notável” ganha destaque o menino Enzo, morador da Serrinha que, na Casa do Jongo, vai andando, esbarrando nas pessoas. Sem camisa, suado, pernas roliças, barrigão à mostra, se aproxima da roda, é notado pelos músicos que apertam sua mão, cumprimentam com sorrisos e sabem que o menino é mexilhão, mexe no pandeiro e pede a todos os músicos para tocar um pouquinho e, independente da resposta, o menino segue metendo a mão. Até porque, mesmo metendo a mão antes do sim e do não, ele é um componente daquela harmonia e já faz parte do samba.

Perseu Silva é autor das crônicas: "Em dia de Parada..." e "Camburão Negreiro". Na primeira, o autor relata uma experiência pessoal vivenciada durante a $23^{\mathrm{a}}$ Parada do Orgulho LGBTQI, quando visualiza policiais, quase todos pretos, correndo atrás de meninos e jovens, também pretos, que roubavam em meio à multidão. Todos pobres. Em paralelo, outros meninos e jovens também pretos, uns empurravam carrinhos vendendo cerveja e água, outros, churrasquinho, outros, recolhiam latinhas do chão. Em meio a essa contradição do capitalismo selvagem, o autor se depara com uma menina, também preta, fantasiada de cisne negro, correndo em volta do pai. Na contradição que é a vida, pai e filha desfilavam contra o ódio. Na segunda, através de uma crítica às oportunidades e tratamento dado ao povo negro, propõe uma reflexão sobre os elos que ainda hoje o aprisionam: foram três séculos de escravidão no Brasil, de 1550 a 1888. Será? Sem se dar conta, uns ainda se consideram melhores do que os outros pois de alguma forma representam o Sistema, sendo todas vítimas deste. 
Nesse conjunto de crônicas, em meia página, Débora Soares faz de "Leituras", uma escrita de esperança e resgate. A autora relata uma cena entre pai e filho dentro de um ônibus: o pai apresenta dificuldade na leitura de um bilhete vindo da escola e o filho o auxilia. A autora compartilha sua percepção: às vezes os papéis se invertem e os pais podem aprender com os filhos.

"Janela do Quintal”, de autoria de Cecília Schubsky, retrata a experiência de contemplar no quintal, através de sua janela, crianças que fazem algazarras entre árvores; a autora considera ter sido transformada pelo tempo numa escutadora de infâncias. A partir de um fato concreto, a autora oportuniza ao leitor uma relevante reflexão acerca da vontade pessoal da criança, do respeito à singularidade.

Caroline Trapp de Queiroz é autora de quatro crônicas. Em "Dia das Crianças" e "Meninos", compartilha experiências vivenciadas em transporte coletivo, o ônibus. Na primeira suscita um questionamento sobre para quais crianças o chamado "Dia da Crianças" de fato existe, considerando realidades distintas, especialmente para aquelas que, nesse mesmo dia, passam horas tentando vender mercadorias dentro dos ônibus e/ou nos sinais de trânsito. Já na segunda relata a experiência de, assim como várias pessoas, se deparar com um menino deitado dentro do ônibus em banco preferencial, dormindo. Por ele todos passam. Olhar de tristeza, indiferença, desprezo. Ninguém o acorda. Uns por não se importarem, outros por saberem que o seu despertar não resolverá as questões que o puseram a dormir. Convida o leitor a refletir sobre o dia do acerto de contas. Um mundo que deveria oferecer possibilidades a esses meninos, mas que há muito deles abriu mão. Morre de medo, mas não morre de vergonha, um dia acertará as contas com eles.

Nas duas crônicas seguintes, "La Casa de Papel(ão)" e "CEP", a autora chama a atenção do leitor para o espaço mais disputado: a rua. A rua quando vira casa. O lar como demarcador. Por todos os lados o papelão, matéria-prima das camas, janelas, paredes, berços.... Uma realidade que testemunha a ruptura entre vida e humanidade. Queiroz propõe uma reflexão em torno de uma desigualdade que amarga a boca.

Núbia Santos é autora das crônicas: "Pique-estátua", "A pele que habito" e "De Novo". Nas duas primeiras crônicas, a autora relata a presença de crianças por espaços até então conhecidos como públicos, mas que nem sempre estão "disponíveis" a todos. Suas vestimentas, cor da pele e marcas que carregam, evidenciam infâncias outras, nas quais viver a condição infantil destoa das que estamos acostumados a vivenciar. 
Em "De novo", a autora relata a relação de afeto de uma criança que aparentemente mora com sua avó num dia que bem pode ser comum. A crônica apresenta uma narração sequencial de fatos. A avó descreve as atitudes que toma com o menino, que do seu jeito tenta dar-lhe dar cuidados e uma educação adequada. Os fatos narrados acontecem a partir da chegada da criança da escola até a hora do jantar. O nome da crônica faz alusão às atitudes da avó e do menino que parecem se repetir todos os dias. O "de novo" que se reveste de afeto e por isso se faz novo, todos os dias.

Patrícia Trindade é autora de "A feira" e "Inteiros". Em "A feira", relata cenas desse espaço tão comum nos bairros do Rio de Janeiro. A chegada dos caminhões, que exalam a fragrância das coisas que carregam, que se misturam às pessoas indo e vindo e que movimentam aquela rua. Chama-lhe a atenção como as crianças e adolescentes utilizam esse espaço como um meio de sustento, carregando compras, vigiando carros, vendendo produtos e ainda há aqueles que pedem dinheiro. Essas crianças e adolescentes também esperam ansiosamente pela xepa que é o término da feira, garimpam o que sobra e assim garantem a comida para suas famílias.

Em "Inteiros", a cena que chama a atenção é a de um menino vendendo balas perto de Bancos que ficam em um centro comercial. Este é avistado encostado na pilastra, próximo à saída de um deles. E de pilastra em pilastra aguarda seus clientes. Está acompanhado por uma menina que segura um bebê, ambos a vender balas. Essas crianças, que não pareciam irmãos, segundo a autora, constituem a "nova" família brasileira. Antes mesmo de tentar vender suas balas para duas senhoras que saíam de um desses bancos, ouve de uma delas: "não tenho trocado, só inteiro", a que o menino sem cerimônia retrucou: "serve inteiro mesmo". Inteiros, defendendo o pão de cada dia, na rua, meninos e meninas.

“O lugar e o menino sem lugar", “50\% menos" e "Livros e panos”, são de autoria de Fernanda Millanez. “O lugar e o menino sem lugar”, começa com a descrição do local onde se passa a cena narrada. É outono e a paisagem muda. Caíque é o personagem principal que, com sua pressa e bicicleta enferrujada, chega ao portão de uma escola municipal, lugar que parece ser bem conhecido. Observa os meninos brincando, uniformizados, enclausurados e lembra que por muitas vezes era ele naquele espaço, chega a procurar um desenho que possa ser seu em um dos murais enfeitados. Mas um carro passa, levanta a poeira e não é mais possível achar os meninos e nem a si mesmo. Monta em sua bicicleta e vai embora faz esquecer que passou por ali, desimprimindo sua marca e sua passagem por aquele lugar.

Em “50\% menos”, Millanez narra uma experiência que viveu em um país como estrangeira. A dificuldade em compreender o idioma faz com que sinta fragilizada e passe por 
uma situação que talvez não fosse preciso. Necessitando alimentar-se acaba por ficar numa fila de um restaurante no qual um letreiro lhe chama a atenção. A fila aumenta e ninguém entra no restaurante. Depois de algum tempo percebe que a entrada só seria permitida às três horas. E, somente quando entra no restaurante, percebe que as pessoas que estão na fila pareciam também estrangeiras e que naquele horário a comida era servida num valor $50 \%$ mais barato do que anunciado no cartaz. Depois de tantas questões que lhe saltaram aos olhos, encosta em um balcão e consegue dar sua primeira garfada, mas percebe que nem tudo que foi escolhido está apropriado para o consumo, olha para o lado e vê uma menina e avó da fila que avistara anteriormente. A menina faz algumas caretas e reclama, mas come quase tudo igual a Fernanda. Diante do gosto azedo e ao mesmo tempo na escolha de comer mesmo assim, para pelo menos se sentir viva, visível, a autora pensa nas pessoas que vivem tal situação não apenas um pedaço do dia, em uma viagem, e sim por um longo tempo, na mais completa invisibilidade.

Em sua última crônica "Livros e panos", Trindade relata a paixão de um menino por livros. Ele torce para chegar ao final, mas quando chega sente saudades. Não gosta de ser interrompido. Mas isso acontece sempre na melhor parte, às vezes dá para fingir que não vê, diz ele, mas às vezes encontra uns mais insistentes. O rebuliço interno que a leitura lhe causa chama a atenção da autora, que ao manter uma conversa com ele logo descobre que o ávido leitor não gosta da escola. O menino muda de assunto e durante a conversa troca informações sobre de onde vem e também pergunta sobre a cidade da autora, que para ele são bem parecidas na distância. Mais do que ler, o menino estava ali para vender seus panos de prato e logo pergunta se não vai levar. A autora vai embora com dois panos de prato e a promessa de voltar levando outros livros. Já indo embora percebe que não é a única que lhe prometeu isso.

Na crônica "Sessão de Cinema", a autora Luciana Bessa narra a experiência de levar trinta crianças de quatro e cinco anos ao cinema numa manhã de quarta-feira. Bessa inicia informando o longo trajeto percorrido por três horas e meia após saírem de Campo Grande, bairro localizado na zona oeste da cidade do Rio de Janeiro, até chegarem à zona sul da cidade. Denuncia, através desse relato, a situação da mobilidade urbana na cidade do Rio de Janeiro, na qual diariamente a população passa longas horas presas no trânsito em trajetos dentro da própria cidade. Em alguns trechos, Bessa revela também algumas situações ocorridas que chamaram sua atenção, tais como: o modo que as crianças foram organizadas após descerem do ônibus, enfileiradas “Um atrás do outro, que nem gafanhoto!", conforme desejava a professora e a alocação das mesmas sentadas no chão da antessala do cinema. Fica da cena a coragem das 


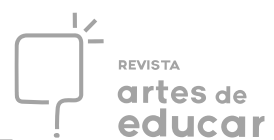

professoras que atravessa a cidade e faz a infância ser, pelo menos por um dia, uma infância que vai ao cinema.

"Encontro" é o título da crônica de Cristina Muniz, na qual relata o encontro com Serginho, menino que vendia coisas no shopping. De metrô, pela primeira vez indo a um ao shopping do subúrbio, na zona norte do Rio de Janeiro, testa sua sensibilidade de pesquisadora que quer encontrar crianças correndo em liberdade. Dizem que aqui isso é possível. Assim, a tentativa é alimentada pela esperança de encontrar essas crianças que a inspiraram ir passear num shopping do subúrbio, pois dizem que lá dá para correr e brincar. Ela, moradora do bairro de Copacabana, confessa que nunca gostou de ir ao shopping, por considerar ser uma ilusão de passeio "uma caixa de vidro rodeada de vitrines que convidam a entrar e consumir aquilo que a gente nem precisa". No entanto, o inusitado encontro com Serginho torna sua aventura descoberta de um amigo que faz do passeio anúncio de uma autonomia precoce, mas que tem infância e tem abraços

“Quando chegar lá...", "Faculdade de marketing" e "Anjinhos" são crônicas de Juliana Viegas. A primeira revela, no decorrer dos fatos, que se trata de uma família cujo pais são separados e que, no feriado da sexta-feira da paixão, as crianças ficaram sob a guarda do pai. No Ramal Santa Cruz a marca na narrativa se entretece entre o abrir e fechar das portas. Nesse movimento que se conecta com a vida familiar, o pai, duas irmãs e um irmão, vão narrando eventos que acontecem da estação Santíssimo até a estação Maracanã. Entre eles, o olhar atento da criança mais nova, percebendo e questionando tudo que avistava, a implicância da irmã mais velha com o irmão, a impaciência do pai com as crianças ao exclamar: "Três dias com vocês, haja paciência!" - anunciam que estão quase perto de chegar lá.

Em “Faculdade de marketing”, Viegas segue relatando o cotidiano do trem, agora o ramal Japeri, enfatizando que chegou à conclusão de que o brasileiro é o rei do marketing e que nos trilhos nascem ótimos slogans, como por exemplo: "Biscoito Copacabana, preço de pobre e gosto de bacana"." Mas, segundo a autora, o rei do marketing é uma criança de uns dez anos desse ramal, que oferece películas de vidro para celular, gritando frases como: "A oportunidade passa, agarra quem tá ligado”.

Por fim, Viegas escreveu "Anjinhos", mais uma viagem no trem ramal Santa Cruz, no qual observou uma criança vendendo o combo de dez pingos de leite por um real, fazendo o uso da expressão "Vê se seu anjinho merece", a fim de tentar convencer os adultos a realizar a compra para seus filhos, sobrinhos e netos. E foi exatamente o modo de vender a mercadoria que 
chamou atenção, pontuando essa observação no trecho "Do alto de sua pouca idade, já sabe prometer adoçar esse encontro é a primeira lei da publicidade."

Patrícia Desterro é autora de "Menina mulher" e “Objeto de Museu”, na primeira ela é a protagonista do que parece ser um diálogo com sua mãe, com quem todos os dias vai de carro até seu trabalho. Desterro sempre fala de sua vida pessoal e de suas amigas. A mãe confessa que até tenta interagir, mas se distrai, às vezes quer rir, mas a sua "passageira" se zanga. E então fica ali a pensar que a menininha cresceu e que é uma mulher como tantas outras: "que vive a vida, que cuida da casa, das filhas e sobrinhas e que tem um companheiro.", confessando segredos de mãe para mãe.

Na segunda, Desterro narra um dia de visita escolar de cerca de 25 crianças da $1^{\text {a }}$ série do Ensino Fundamental ao Museu Nacional. Revelando o olhar curioso e criativo das crianças, que transformam o banco em escorrega. Além disso, a autora denuncia no trecho: "Criançada curiosa, falatório geral. Professora pede silêncio. Mediadores se olham, um misto de nervoso e ansiedade" a necessidade de controle do adulto sobre os corpos pequenos, pedindo silêncio e atenção.

O livro "Infância Crônica" apresenta fatos do cotidiano que, possivelmente, já apareceram na vida de qualquer pessoa. As crônicas ricas em detalhes têm como protagonistas as crianças e sua cultura, relacionada com a cidade. Numa linguagem cativante e ao mesmo tempo que inquieta o leitor, os autores das crônicas apontam que é na vida cotidiana que a dimensão da política da infância se funda. Ao revelar a presença das crianças no cotidiano, nem sempre perfeito, procuram sensibilizar o leitor, possibilitando que o mesmo se identifique e se transporte para as cenas que estão sendo narradas, encontrando ali sua própria infância. Não podemos sair dessa leitura do mesmo modo como chegamos. A leitura de Infância Crônica é, antes de tudo, uma convocação à nos posicionarmos diante da infância.

\section{REFERÊNCIAS}

VENAS, R.; RIBES, R. (Org). Infância Crônica. 1.ed. Rio de Janeiro: NAU, 2019.

iPossui graduação em Pedagogia pela Universidade do Estado do Rio de Janeiro (2015). Especialista em Gestão Educacional Integrada e Psicopedagogia Institucional e Clínica. Professora de Educação Infantil nos municípios de Itaguaí e Rio de Janeiro. Mestranda em Educação, Contextos Contemporâneos e Demandas Populares pela Universidade Federal Rural do Rio de Janeiro (PPGEduc/UFRRJ), membro do Grupo de Pesquisa Infâncias até dez 
anos (GRUPIS/UFRRJ). E-mail: amandapfinfo@gmail.com Rio de Janeiro/RJ. ORCID: https://orcid.org/00000003-1443-6908

iiPossui graduação em Pedagogia pela Universidade do Estado do Rio de Janeiro (2010). Especialista em Gestão Integrada. Professora de Educação Infantil no município de Belford Roxo e Nova Iguaçu. Mestranda em Educação, Contextos Contemporâneos e Demandas Populares pela Universidade Federal Rural do Rio de Janeiro (PPGEduc/UFRRJ), membro do Grupo de Pesquisa Infâncias até dez anos (GRUPIS/UFRRJ). E-mail: nandaalmeidaf@gmail.com Petrópolis/RJ. ORCID: https://orcid.org/0000-0003-2911-7264

iii Possui graduação em Pedagogia pela Universidade Federal Fluminense (2005). Especialista em Docência na Educação Infantil e Psicopedagogia Institucional e Clínica. Professora de Educação Infantil no município de Niterói. Mestranda em Educação, Contextos Contemporâneos e Demandas Populares pela Universidade Federal Rural do Rio de Janeiro (PPGEduc/UFRRJ), membro do Grupo de Pesquisa Infâncias até dez anos (GRUPIS/UFRRJ). Email: flavialucena81@gmail.com Duque de Caxias/RJ. ORCID: https://orcid.org/0000-0002-3032-9320 